\title{
Diagnostics of cycloidal gear speed reducers in vertical multirotor system
}

\author{
V. Barzdaitis*, V.V. Barzdaitis**, K. Kazlauskiené***, A. Tadžijevas**** \\ *Kaunas University of Technology, Studentu str. 56-332, 51424, Kaunas, Lithuania, E-mail: vytautas.barzdaitis@ktu.lt \\ **Vytautas Magnus University, Vileikos str. 8, 44404, Kaunas, Lithuania, E-mail: v.barzdaitis@if.vdu.lt \\ ***Kaunas University of Technology, Studentu str. 56-345, 51424, Kaunas, Lithuania, \\ E-mail: kristina.kazlauskiene@ktu.lt \\ ****Klaipéda University, Bijūnu str.17, 91225, Klaipėda, Lithuania, E-mail: tadzijevas@gmail.com \\ cross $^{\text {ref }}$ http://dx.doi.org/10.5755/j01.mech.23.2.14907
}

\section{Introduction}

High productivity vertical axis rotating diffusion machine driven by multiple drives is complicated system for technical condition monitoring, diagnostics and failure prognosis. The failure diagnostic problems of vertical axis rotating machine driven by ten cycloidal gear reducers is complicated from practical diagnostics point of view using vibration monitoring parameters [1]. Unlike many others gear power transmissions the cycloidal gear driver is not typically back drivable and in case of only one drive failures it may cause failure of driving involute pinion tooth or in worst case - failure of expensive driven gear. The operation of cycloidal gear drive is based on the eccentric motion nature of the cycloidal disc. Generally each cycloidal gear drive includes two subsystems - high and low rotational speed stages. Each stage comprises two cycloidal discs. The two stages cycloidal gear drive has many antifriction bearings with additional 2 bearings of output rotor with involute pinion tooth. Such design scheme drive is perfectly balanced and eliminates rotor unbalance caused vibration [2-4]. The cycloidal gear drives severe vibration mainly caused by antifriction bearings failures. In industry the electric motor and drive defects diagnostics are concentrated on machine mechanical vibration periodic monitoring in situ. This is one of several stages of technical condition assessment of whole rotating system in general and each element in particular. The traditional rotating machinery diagnostic methods described in International Standards (ISO 13373-1:2002, ISO 13373-2:2005, ISO 13379:2003, ISO 2954:2012, ISO 7919 and ISO 10916, etc.). All of those methods are used in practice. But it is a general view in fault diagnostics technique, but not acceptable for different design machines and specific operation conditions. In this work we put attention of fault diagnostics of vertical rotating system simultaneously running with ten cycloidal gear drives with doubled crankshafts and antifriction bearings. The experimental research was based on each drive absolute vibration measurements data in situ at full load of diffusion machine operation.

\section{Research object}

The general scheme of diffusion machine with ten cycloidal gear drives is shown in Fig. 1. Cycloidal drive represent first CR1 and second CR2 stages and has the same design scheme but difference in geometrical size reference to large output rotor $3 \mathrm{v}$ torque.

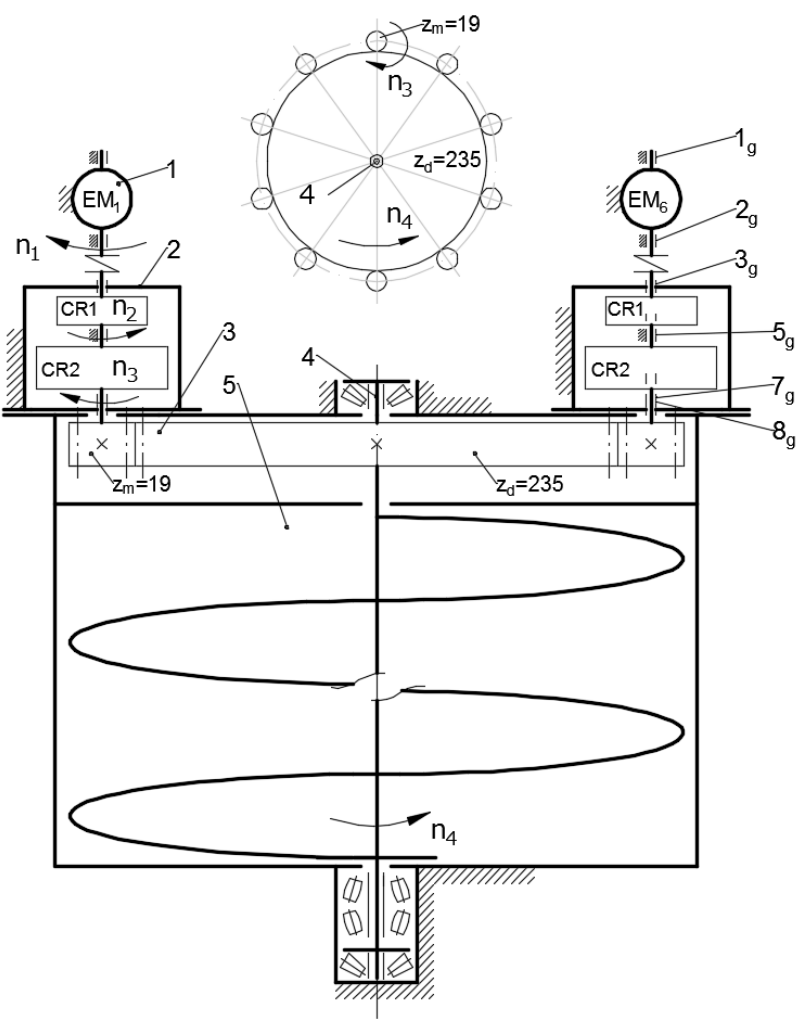

Fig. 1 Vertical axis diffusion machine: 1 - electric motors (EM1,..,EM10); 2 - ten cycloidal gear reducers (CR1 - first and CR2 - second stage); 3 -involute tooth gear reducer (pinion $z_{m}=19$ and gear $z_{d}=235$, tooth module $m=2 \mathrm{~mm}$, reduction ration 12,3684); 4 - vertical axis screw-rotor (rotation speed $n_{4}=0,16985 \mathrm{rpm}$ ) with antifriction bearings; 5 - machine cylinder; $3 \mathrm{~g}, 5 \mathrm{~g}, 7 \mathrm{~g}, 8 \mathrm{~g}-$ antifriction bearings of cycloidal gear reducer

CR1 has two cycloidal discs with $z_{1}=17$ lobes each and ring gear pins/rollers $z_{2}=18$ with reduction ratio $u_{1}=\left(z_{2}-z_{1}\right) / z_{1}=(18-17) / 17=1 / 17$. At nominal load the CR1 crankshaft input rotation speed is $n_{1}=750 \mathrm{rpm}$ the first stage output shaft as CR2 second stage input shaft with 12 rollers rotation speed is $n_{2}=750 / 17=44,1176 \mathrm{rpm}$. The CR1 crankshaft 1e with two eccentric bearings in two cycloidal discs provides rocking motions and excites radial forces acting on the cycloidal discs with 17 lobs. The cycloidal disc lobes enter in the ring gear pins/rollers and each cycloidal disc fulfils a planetary rotation as the crankshaft rotates. The CR1 driving crank- 
shaft has two eccentric bearings, each fixed in the separate cycloidal disks with $180^{\circ}$ phase difference. Such design scheme compensates crankshaft unbalance, decrease vibration intensity and increase reliability of cycloidal speed reducer.

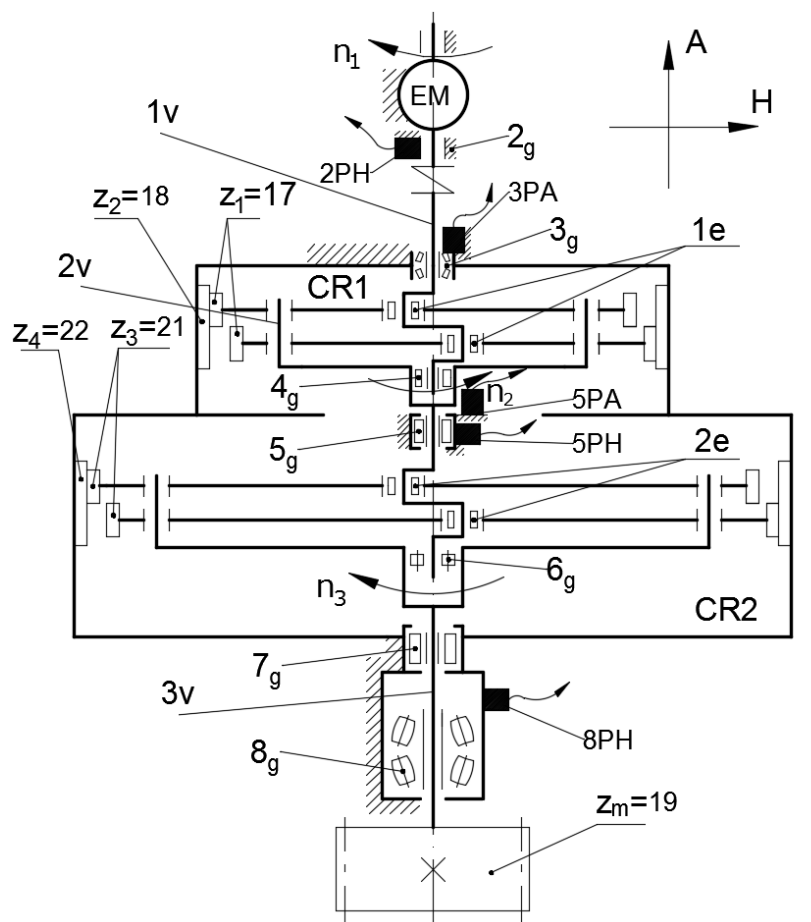

Fig. 2 Kinematic scheme of two stages CR1, CR2 cycloidal gear reducer (coupling ratio $u=357$ ) with absolute vibration measurement transducers locations: $1 \mathrm{v}-\mathrm{CR} 1$ first stage crankshaft with two eccentric bearings $1 \mathrm{e} ; 2 \mathrm{v}-\mathrm{CR} 2$ second stage crankshaft with two eccentric bearings $2 \mathrm{e} ; 3 \mathrm{v}$ - output rotor; transducer 2PH-EM 2g bearing $H$; transducer 3PA-CR1 $3 \mathrm{~g}$ (SKF 21310) bearing $A$; 4g (SKF NJ 407); transducer 5PA- CR2 $5 \mathrm{~g}$ bearing (SKF NJ 407) A; transducer 5PH - CR2 5g bearing $H$; $6 \mathrm{~g}$ (SKF NJ2217E); transducer $8 \mathrm{PH}$-output rotor $7 \mathrm{~g}$ (SKF NJ417) and $8 \mathrm{~g}$ (SKF 22234) bearing H ( $H$ - radial direction, $A-$ axial direction)

The second stage CR2 design is analogous as CR1 and includes two cycloidal discs with $z_{3}=21$ lobes each and ring gear with ring gear pins/rollers $z_{4}=22$, Fig. 2. The reduction ratio of CR2 is $u_{2}=\left(z_{4}-z_{3}\right) / z_{3}=(22-21) / 21=1 / 21$. When the first stage output crankshaft $2 \mathrm{v}$ rotation speed is $n_{2}=44,1176 \mathrm{rpm}$ the second stage CR2 output shaft $3 \mathrm{v}$ with 12 rollers rotation speed is $n_{3}=44,1176 / 21=2,1008 \mathrm{rpm}$. The CR2 second stage output shaft with involute tooth pinion $z_{m}=19$ rotates driven vertical axis large gear $z_{d}=235$ connected with screw-rotor 4 at low rotation speed $n_{4}=0.16985 \mathrm{rpm}$, as show in Fig. 1 . The damaged inner ring raceway of eccentric bearings of crankshaft $2 \mathrm{e}$ is shown in Fig. 3. The reason of damages is eccentric bearings raceways material fatigue, because CR was in exploitation long period. The identification of technical condition of eccentric bearings in practice is complicated, because rotating system has many antifriction bearings and generates random vibration as plotted in very rich spectrum.

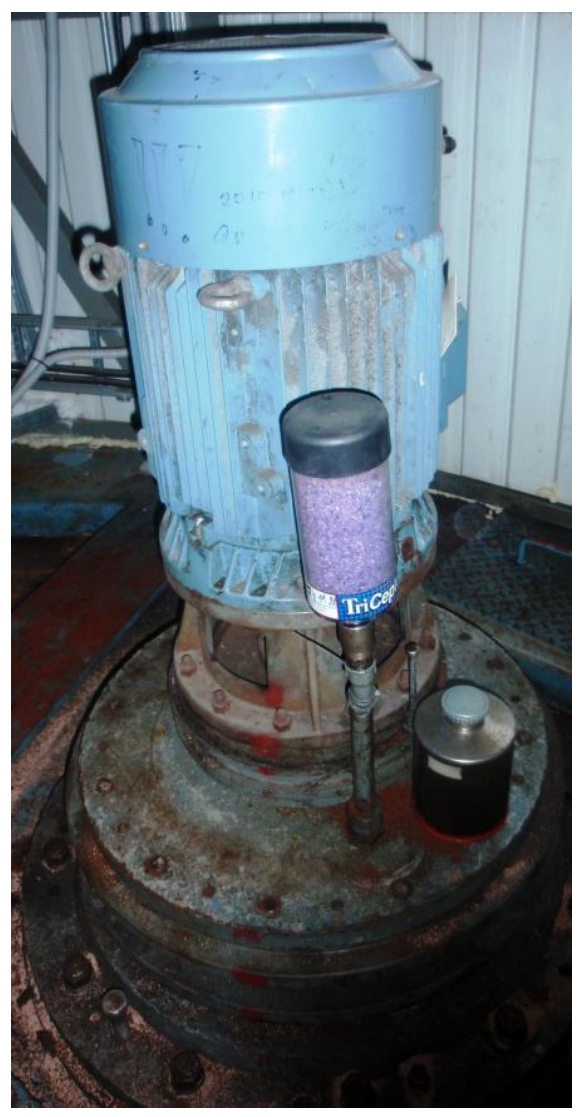

a

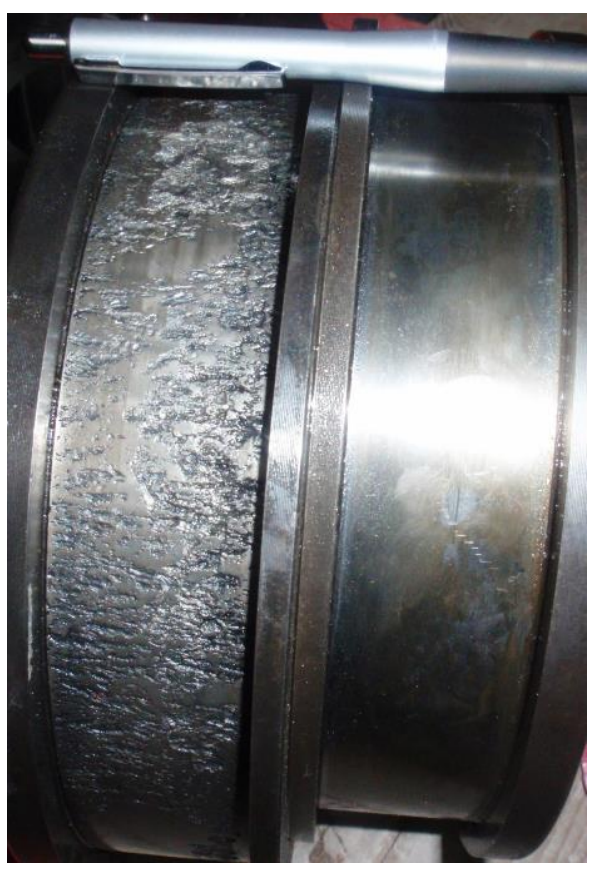

b

Fig. 3 The EM with CR drive and damaged eccentric bearing raceway of $\mathrm{CR} 2$ stage: a - CR with EM; $\mathrm{b}$ - CR2 damaged eccentric bearing raceway

\section{Vibration measurement data and results}

Bearings housings absolute vibration was measured with pjezoaccelerometers 2PH, 3PA, 5PA, 5PH and $8 \mathrm{PH}$ (sensitivity $100 \mathrm{mV} / \mathrm{g}$, resonance frequency $22 \mathrm{kHz}$ ) in two directions: radial $(H)$ and axial $(A)$ reference to vertical 
axis of rotation. Measurement data was analysed with Vibration signal analysers (Ahash A4300, A4101, CZ). The pjezoaccelerometers were attached at 5 local points on CR1 and CR2 bearing housings as shown in Fig. 2. Too many measurement points used to pick up main points that measurement data effectively helps to identified main vibration parameters and increased accuracy of evaluation of technical condition of CR1 and CR2 in general and crankshafts eccentric bearings in particular. The many years diagnostics practice indicated that some cycloidal speed reducer elements (cycloidal discs, ring gear pins/rollers, the crankshafts with main two bearings) are sufficiently reliable in comparison with the technical condition of crankshafts eccentric bearings. The main accent of this research was put on technical condition monitoring of whole drive, especially of crankshaft's two eccentric bearings. Because in case of these bearings failure cycloidal speed reducer can damaged pinion or gear involute tooth $z_{m}, z_{d}$ as practical diagnostic data indicated.

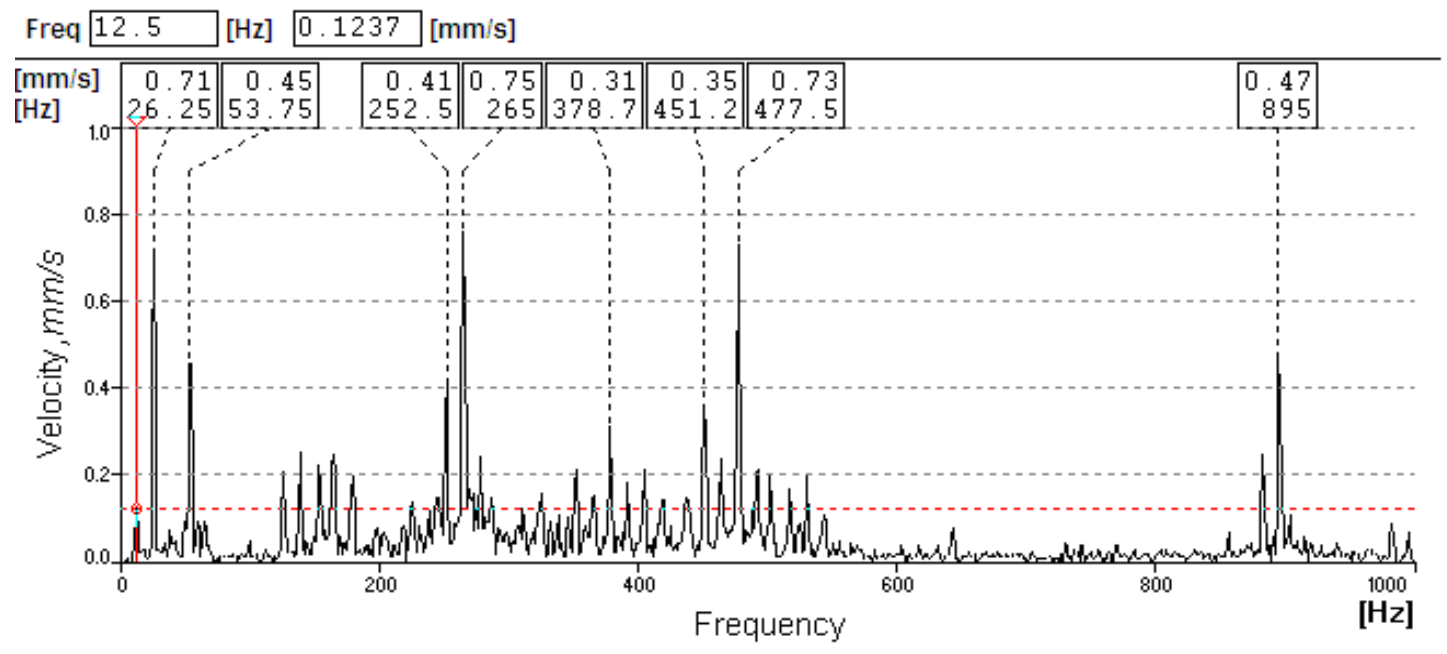

a

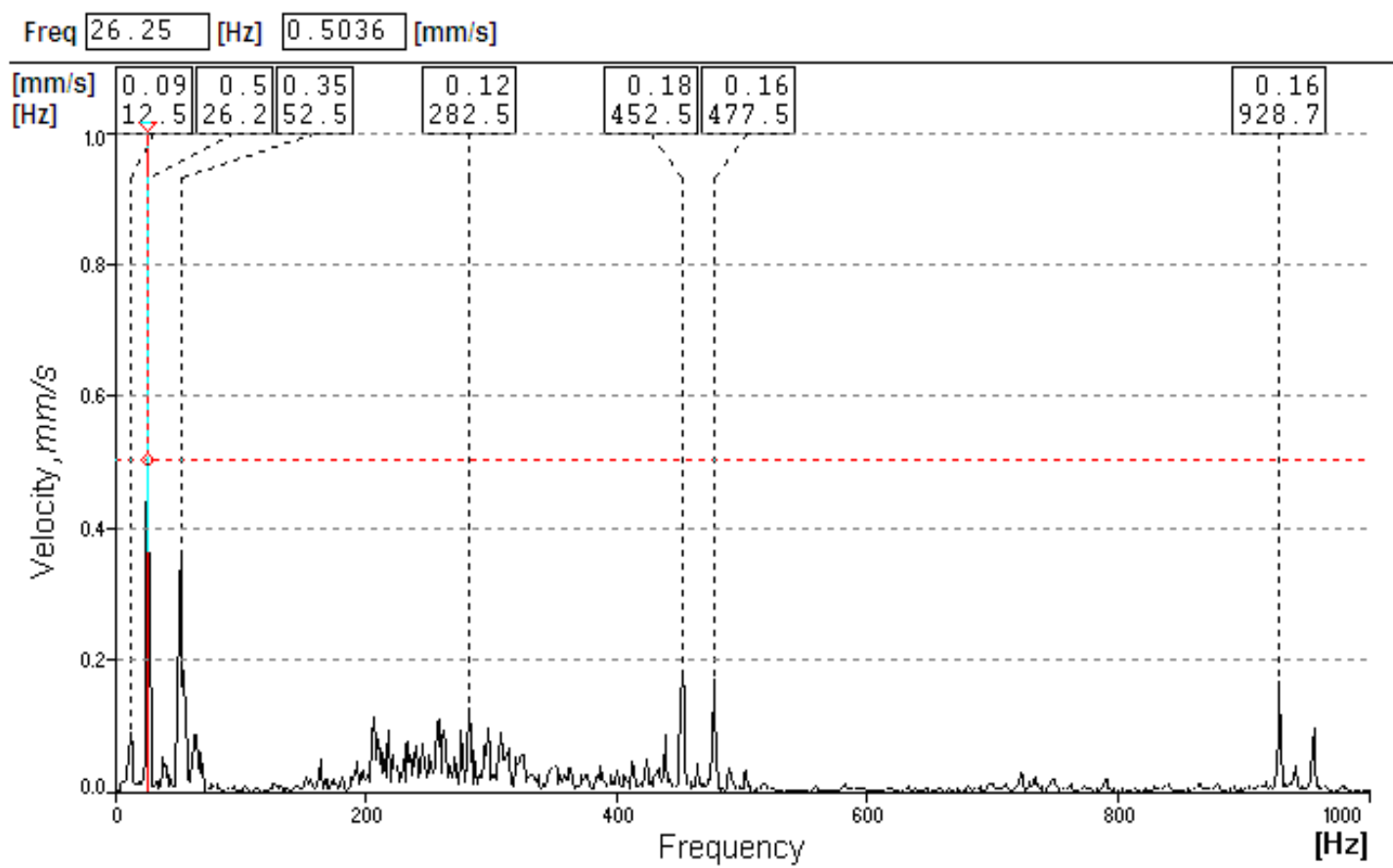

b

Fig. 4 Radial vibration velocity spectra of damaged 1 st and undamaged 6th drives, $2 \mathrm{PH}$ transducer: a - damaged 1st drive, $v_{r m s 2 G H}=1,71-2,23 \mathrm{~mm} / \mathrm{s}, \quad g_{r m s 2 G h}=0,25 \mathrm{~g}, \quad a_{r m s 2 G H}=16,86 \mathrm{~m} / \mathrm{s}^{2}, \quad a_{\max 2 G H}=40,5 \mathrm{~m} / \mathrm{s}^{2} ; \quad \mathrm{b}$ - undamaged 6th drive, $v_{r m s 6 G H}=1,02 \mathrm{~mm} / \mathrm{s}, g_{r m s 6 G h}=0,18 \mathrm{~g}, a_{r m s 6 G H}=6.09 \mathrm{~m} / \mathrm{s}^{2}, a_{\max 6 G H}=14.8 \mathrm{~m} / \mathrm{s}^{2}$

The damaged (1st drive) and undamaged (6th drive) drives 2 nd bearings vibration velocities spectra measured in radial direction with $2 \mathrm{PH}$ transducer is shown in Fig. 4, a, b. Rich vibration velocity spectrum in Fig. 4, a indicates technical condition problems in vertical drive CR1 shaft $1 \mathrm{v}$ with two eccentric bearings. CR1 $1 \mathrm{v}$ driving shaft $1 v$ rotates at $750 \mathrm{rpm}(12.5 \mathrm{~Hz})$. The double crankshaft ex- citation frequency is $2 \mathrm{X} / 26.25 \mathrm{~Hz}$ and vibration velocity amplitude $0.71 \mathrm{~mm} / \mathrm{s}, \quad 265 \mathrm{~Hz} / 26.25 \approx 10 \mathrm{X}$ harmonic $0,75 \mathrm{~mm} / \mathrm{s}$ and $477.5 \mathrm{~Hz} / 26.25 \mathrm{~Hz} \approx 18 \mathrm{X}$ harmonic $0.73 \mathrm{~mm} / \mathrm{s}$ and dominated in the vibration velocity spectrum, Fig. 4, a. There are no vibration velocity dominated amplitudes values that could be proportional to bearings kinematic frequencies of CR1 stage: spherical roller bearing 
3g SKF 21310, cylindrical roller bearings 4g and 5g single row NJ407, 4g and NJ417, $5 \mathrm{~g}$ (see Fig. 2).

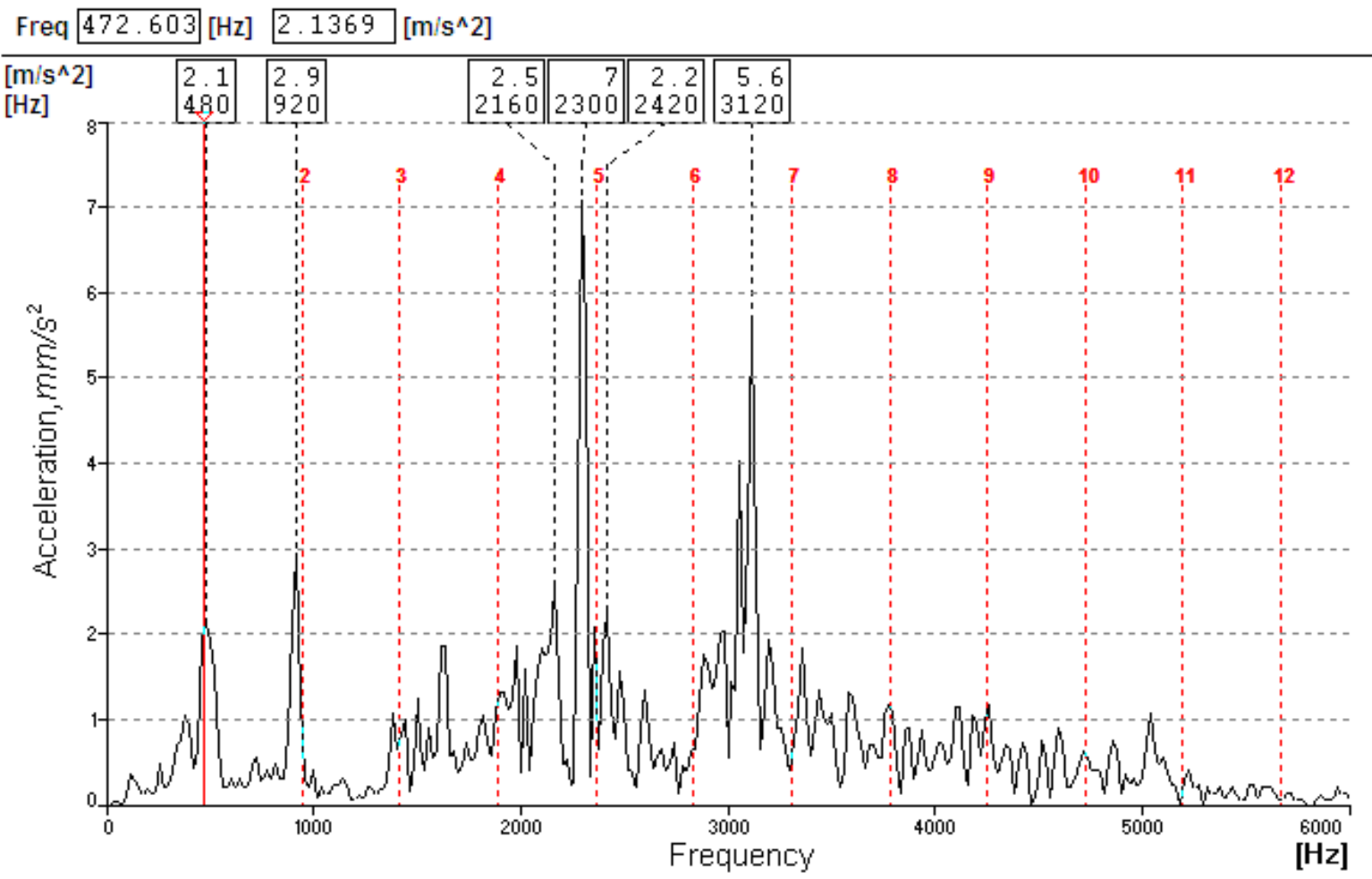

a

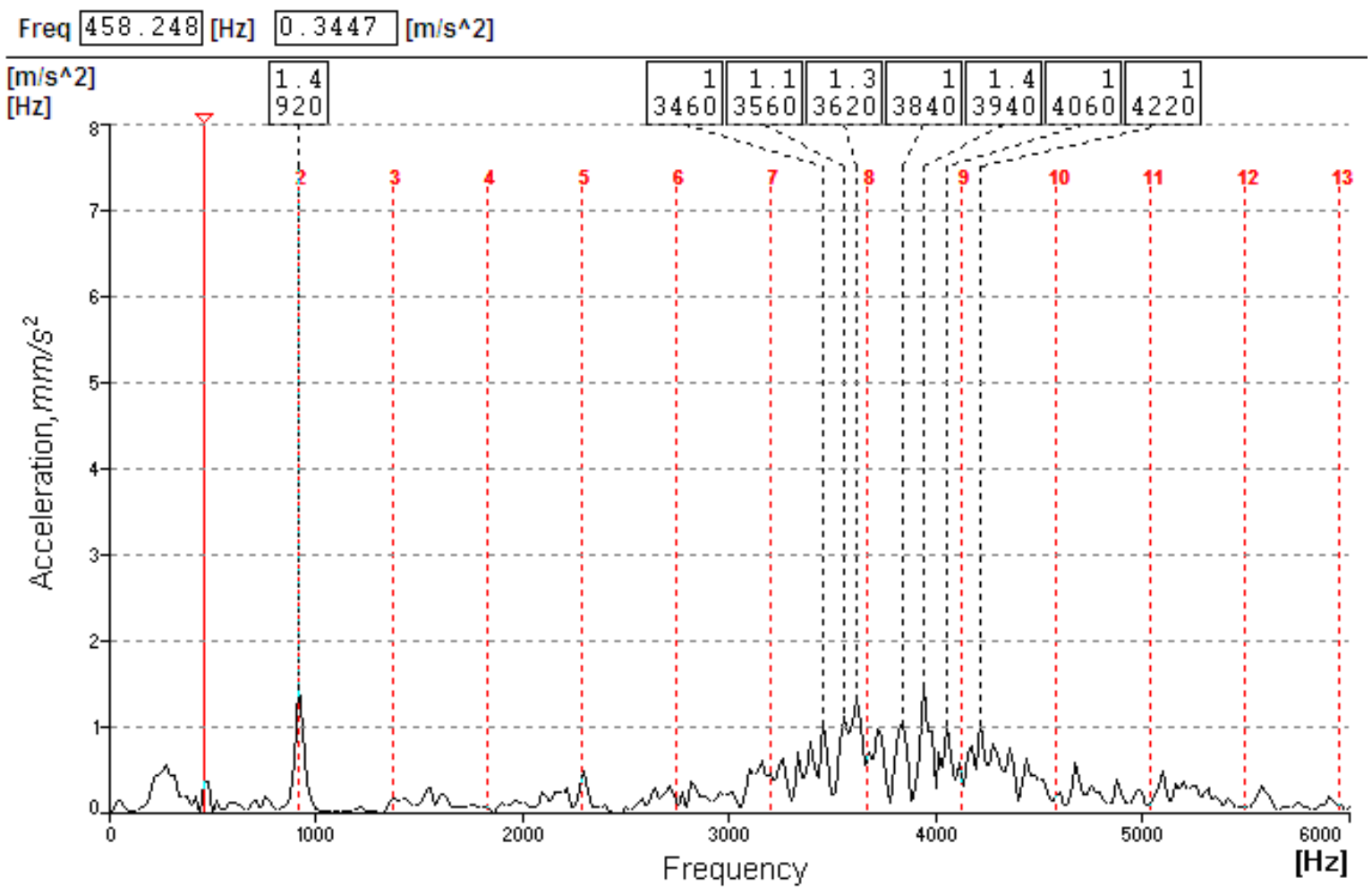

$\mathrm{b}$

Fig. 5 Radial vibration acceleration spectra of damaged 1st and undamaged 6th drives, $2 \mathrm{PH}$ transducer: a - damaged 1st drive; $b$ - undamaged 6th drive

The damaged and undamaged $\mathrm{CR}$ drives 2 nd bearings vibration acceleration spectra measured in radial direction with $2 \mathrm{PH}$ transducer is shown in Fig. 5, a, b. The high frequency vibration acceleration amplitudes are more informative for identification of damaged CR drive. The vibration measurement data received from axial direction measurement transducer 3PA indicated the same result (Fig. 6, a, b), that high frequency $(2000-5000 \mathrm{~Hz})$ vibration acceleration is more informative in diagnostics in comparison with low frequency vibation velocities. 
Vibration date that received from transducers 5PA, $5 \mathrm{PH}$ and $8 \mathrm{PH}$ there are not informative for identification of $\mathrm{CR}$ drive bearings technical condition monitoring as pactical test in situ CR indicated.

Diagram in Fig. 7 indicates that absolute vibration acceleration arms values measured with $2 \mathrm{PH}$ and $3 \mathrm{PA}$ transducers are dominated in diagram in comparison with 5GA and 5GH measured data. These results implemented in practical solutions for evaluation of technical condition of CR drives in industry. The high frequency (up to $5000 \mathrm{~Hz}$ ) vibration acceleration root mean square values arms are more informative for eccentric bearings raceways multiple damages diagnostics. The parameter , $\mathrm{g}^{\text {" }}$ is not acceptable for evaluation because it is involved vibration frequencies overcomes $5000 \mathrm{~Hz}$.

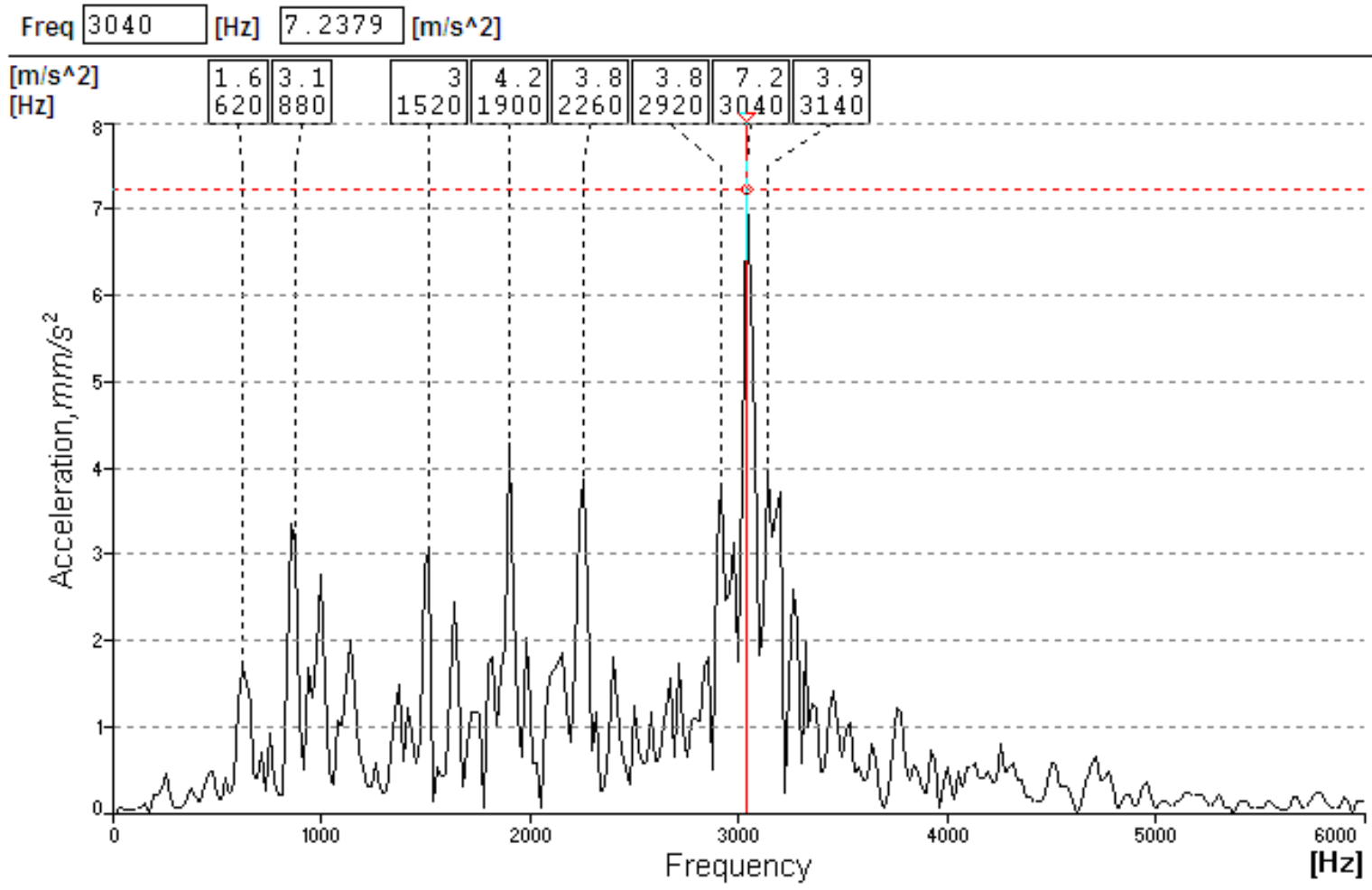

a

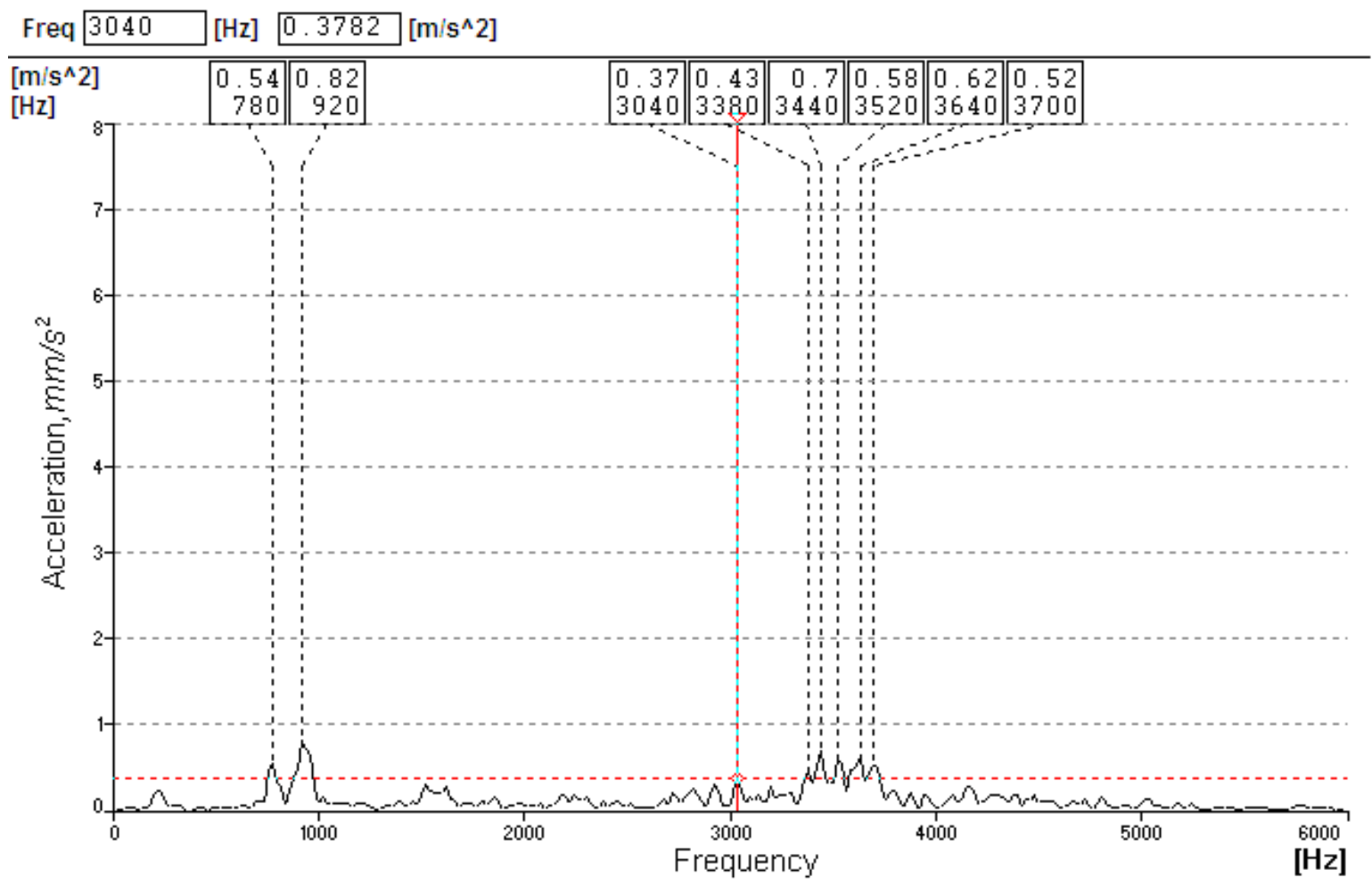

b

Fig. 6 Axial vibration acceleration spectra of damaged 1st and undamaged 6th drives, 3PA transducer: a - damaged 1st drive, $\mathrm{b}$ - undamaged 6th drive 


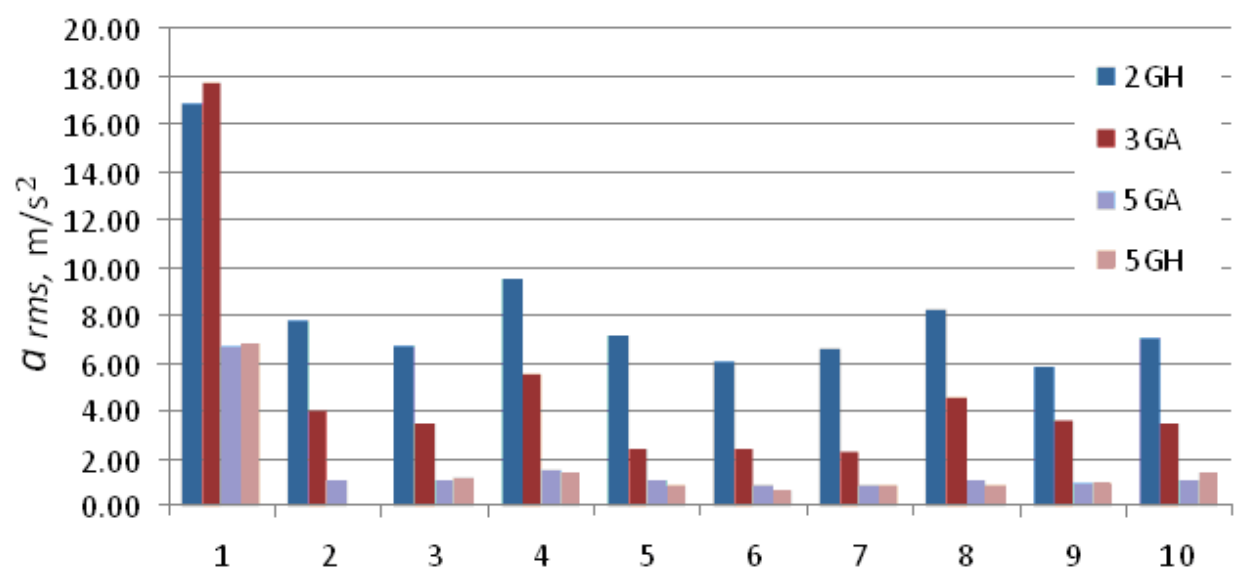

Fig. 7 Vibration severity diagram of ten CR cycloidal speed reducers reference to 4 measurement points

In conclusion for evaluation of technical condition of CR eccentric bearings authors suggested for practical use vibration acceleration arms parameter measured with $2 \mathrm{PH}$ and 3PA transducers. According to Fig. 5, the vibration severity of CR damaged 1 st drive reached dangerous vibration acceleration $\left(\operatorname{arms} 1 \approx 18 \mathrm{~m} / \mathrm{s}^{2}\right.$ ) values measured with $2 \mathrm{PH}$ and 3PA transducers. The 2nd ,..., 10th drives vibration severity is low. The vibration acceleration arms data that received from 5GA and 5GH transducers are less informative in diagnostics, because vibration energy at indicated locations on CR dissipated in housing material.

\section{Conclusions}

1. Vertical axis cycloidal gear speed reducers with antifriction bearings failure diagnostics can be successful when systematic condition monitoring procedure is provided with seismic transducers attached to $\mathrm{CR}$ first stage CR1 bearing housings in radial and axial directions.

2. The CR first stage CR1 rotor doublet crankshaft excited vibration velocity amplitude is dominated in all ten drives $26.2 \mathrm{~Hz}=2 X$ in comparison with CR1 stage rotor synchronized rotation $1 X$ frequency.

3. The high frequency (up to $5000 \mathrm{~Hz}$ ) vibration acceleration root mean square value $a_{r m s}$ is more informative parameter in comparison with vibration velocity parameter measured up to $1000 \mathrm{~Hz}$ frequency, according to ISO 10816 norms.

\section{References}

1. Barzdaitis, V.; Grigonienė, J.; Mažeika, P.; Tadžijevas, A. 2012. Modeling and diagnostics of vertical axis rotary system driven by multi gear drive, Journal of Vibroengineering 14(1): 171-177.

2. Shyi-Jeng Tsai; Ching-Hao Huang; Hisian-Yu Yeh; Wei-Jhen Huang 2015. Loaded tooth contact analysis of cycloid planetary gear drives, Proceedings of the 14th IFToMM2015 World Congress, Taipei, Taiwan,
953-960

http://dx.doi.org/0.6567/IFToMM.14TH.WC.OS6.014.

3. Wei-Pu Kao; Chang-Chia Hsieh; Jyh-Jone Lee 2015. Computer-aided kinematic error analysis of a two-stage cycloidal drive, Proceedings of the 14th IFToMM2015 World Congress, Taipei, Taiwan, 946-952.

http://dx.doi.org/10.6567/IFToMM.14TH.WC.OS6.013

4. JSC "Darali drives" What is a Cycloidal Speed Reducer? [accessed 3 January. 2016]. Available from Internet: http://www.darali.com/pages21,22.html.

V. Barzdaitis, V.V. Barzdaitis, K. Kazlauskienè, A. Tadžijevas

\section{DIAGNOSTICS OF CYCLOIDAL GEAR SPEED REDUCERS IN VERTICAL MULTIROTOR SYSTEM}

S u m m a r y

This paper deals with failure diagnostic problems of vertical axis rotating machine driven by ten cycloidal gear reducers with high coupling ration. The cycloidal gear drive is not back drivable device and in case of only one cycloidal drive failure from ten simultaneously running it may cause serious failure of expensive driven involute gear tooth. The main task of ten cycloidal gear reducers research - identification of vibration sources and determined parameters in attempt to evaluate technical condition of each cycloidal drive, especially technical condition of crankshafts eccentric antifriction bearings. Authors suggested effective cycloidal gear speed reducer main bearings high frequency vibration monitoring procedure, based on long term research data provided in industry.

Keywords: vertical axis multi drive system, cycloidal gear reducer, vibration, failure diagnostics.

Received May 04, 2016 Accepted April 14, 2017 